\title{
PME aiming for quality, originality and peer recognition
}

\author{
Griet Peeraer
}

Published online: 22 May 2012

(C) The Author(s) 2012. This article is published with open access at Springerlink.com

When asked about criteria for assessing quality in academic research, 94 scientists working in the domain of health research but coming from different backgrounds (biomedicine, medicine and social sciences) believed that peer-reviewed articles were still the best academic achievement indicators [1].

According to Albert's study, the three interrelated arguments that were emphasized when talking about peer-reviewed published articles were quality, originality, and peer recognition of the studies.

\section{In this issue of PME}

PME is a peer-reviewed journal and in my view the same three arguments should be considered when reading the manuscripts submitted to PME. In Wingelaar's article [2] on student's educational needs for clinical reasoning in first clerkships, we note that the results of this study underscore the importance of learning in a clinical setting. Intrinsic motivation for learning is enhanced when students take care of real patients; they feel a stronger need to learn how to perform effectively compared with being trained in a simulated situation.

According to literature on self-efficacy, however, most students overestimate their capabilities. According to Artino [3], medical students who overestimate their selfefficacy may possess high confidence in their ability to draw blood after having learnt the skill, but yet may fail to draw blood correctly from a patient in a clinical setting.

The two articles are both original, of good quality and have been recognized by peers. They provide interesting information and a challenge for further research. The information given by PME articles will hopefully fuel the debate on simulated learning and workplace-based 'real life' learning.

G. Peeraer $(\bowtie)$

Faculty of Medicine and Health Sciences, University of Antwerp, Antwerp, Belgium email: Griet.peeraer@ua.ac.be 
A different debate in medical education research is the one on applying research methods from the clinical research paradigm in education research [4]. Randomized controlled trials (RCT) have traditionally been perceived as the strongest design for research [5]. Salina et al. [6] chose the RCT method to study the effectiveness of YouTube for the learning of a nursing technique and found that video represents an important learning tool to refresh and reinforce supporting student learning. In this technological era, YouTube as a video-sharing website is known to almost everyone. When this and the next generation(s) of students grow up with media in a way totally different from former generations, aspects such as educational approaches, instructional design have to change.

As Sir Ken Robinson stated in his lecture Changing Education Paradigms [7], we are still shaping the future by doing what people did in the past. Therefore, educational research on the use of new media in classrooms should be promoted. There is a need for thorough research on this topic, with research methods adapted to the educational environment.

Other contributions to this PME issue focus on faculty and student perceptions of the feasibility of individual student-faculty meetings [8], on cognitive outcomes in a pre-clinical bioethics course [9] and on the Ph.D. thesis by Dr. K. Overeem [10]. She has developed a new system for doctor performance assessment and found evidence on how we might optimize multisource feedback in improving doctor performance.

\section{PME and the future}

It is in the best interest of medical education and the training of future doctors that research on medical education keeps growing.

Research in medical education is a relatively young domain. It draws upon scientific principles from a variety of domains/disciplines. The different disciplines have shared assumptions about what 'good' science is, what methods are best to generate valid results, how data should be collected and interpreted, et cetera [11]. Medical education research is a domain that is open to collaboration and to research methods from other disciplines. PME as a journal will try to reflect this view in the choice of its articles.

Conflict of interest The author reports no conflict of interest.

Open Access This article is distributed under the terms of the Creative Commons Attribution License which permits any use, distribution, and reproduction in any medium, provided the original author(s) and the source are credited.

\section{References}

1. Albert M, Laberge S, McGuire W. Criteria for assessing quality in academic research: the view of biomedical scientists, clinical scientists and social scientists. High Educ. 2012. doi:10.1007/s10734012-9519-2.

2. Wingelaar TT, Wagter JM, Arnold AER. Students' educational needs for clinical reasoning in first clerkships. Perspect Med Educ. 2012;1. doi:10.1007/s40037-012-0010-7. 
3. Artino AR. Academic self-efficacy: from educational theory to instructional practice. Perspect Med Educ. 2012;1. doi:10.1007/s40037-012-0012-5.

4. Sullivan GM. Getting off the 'gold standard': randomized controlled trials and education research. J Grad Med Educ. 2011;3(3):285-9.

5. Ringsted C. Research in medical education. Notfall Rettungsmed. 2009;12(Suppl 2):57-60.

6. Salina L, Ruffinengo C, Garrino L, et al. Effectiveness of an educational video as an instrument to refresh and reinforce the learning of a nursing technique: a Randomized Controlled Trial. Perspect Med Educ. 2012;1. doi:10.1007/s40037-012-0013-4.

7. http://www.youtube.com/watch?v=zDZFcDGpL4U.

8. Mulder BF, Erich MH, Borleffs JCC, Elgersma AF, Cohen-Schotanus J. Faculty and student perceptions of the feasibility of individual student-faculty meetings. Perspect Med Educ. 2012;1. doi: 10.1007/s40037-012-0011-6.

9. Fernandes AK, Borges N, Heather Rodabaugh H. Measuring cognitive outcomes in a pre-clinical bioethics course. Perspect Med Educ 2012;1. doi:10.1007/s40037-012-0014-3.

10. Overeem K. Doctor performance assessment: development and impact of a new system. Perspect Med Educ. 2012;1. doi:10.1007/s40037-012-0009-0.

11. Albert M, Laberge S, Hodges B. Boundary work in the health research field: biomedical and clinician scientists' perceptions of social science research. Minerva. 2009;47(2):171-94.

\section{Author Biography}

Griet Peeraer has degrees in Cultural Studies and in Anthropology. She obtained a Ph.D. in medical education and works at the Faculty of Medicine and Health Sciences (University of Antwerp) where she is involved in curriculum management and faculty development. 